\title{
Assessment of the cost effectiveness of compulsory testing of introduced animals and bulk tank milk testing for bovine viral diarrhea in Japan
}

\author{
Norikazu ISODA ${ }^{1,2)}$, Akihiro ASANO ${ }^{3)}$, Michiru ICHIJO ${ }^{3)}$, Hiroshi OHNO4), \\ Kazuhiko SATO5), Hirokazu OKAMOTO'), Shigeru NAKAO'), Hajime KATO'), \\ Kazuma SAITO ${ }^{8)}$, Naoki ITO9), Akira USUI ${ }^{4)}$, Hiroaki TAKAYAMA ${ }^{3)}$, \\ Yoshihiro SAKODA ${ }^{2,10) *}$ \\ 1)Unit of Risk Analysis and Management, Research Center for Zoonosis Control, Hokkaido University, \\ Kita 20, Nishi 10, Kita-ku, Sapporo, Hokkaido 001-0020, Japan \\ ${ }^{2)}$ Global Station for Zoonosis Control, Global Institute for Collaborative Research and Education (GI-CoRE), \\ Hokkaido University, Sapporo, Hokkaido 001-0020, Japan \\ 3)Hokkaido Nemuro Livestock Hygiene Service Center, 69, Betsukai-Midorimachi, Betsukai, Notsuke-gun, \\ Hokkaido 086-0214, Japan \\ 4)Hokkaido Veterinary Medical Association Nemuro Branch, 119, Betsukai-Midorimachi, Betsukai, \\ Notsuke-gun, Hokkaido 086-0292, Japan \\ ${ }^{5)}$ Western Nemuro Operation Center, Hokkaido Higashi Agricultural Mutual Aid Association, \\ 109, Nishi-Syunbetsu, Betsukai, Notsuke-gun, Hokkaido 088-2576, Japan \\ ${ }^{6)}$ Northern Nemuro Operation Center, Hokkaido Higashi Agricultural Mutual Aid Association, \\ 37, Tawara-bashi 14, Naka-shibetsu, Sibetsu-gun, Hokkaido 086-1137, Japan \\ 7)Southern Nemuro Operation Center, Hokkaido Higashi Agricultural Mutual Aid Association, \\ 119, Betsukai-Midorimachi, Betsukai, Notsuke-gun, Hokkaido 086-0292, Japan \\ ${ }^{8)}$ Betsukai Town Office, 280, Betsukai-Tokiwa, Betsukai, Notsuke-gun, Hokkaido 086-0205, Japan \\ 9)The Federation of Agricultural Cooperatives in Nemuro, 2, Higashi 1, Minami 1, Naka-shibetsu, Sibetsu-gun, \\ Hokkaido 086-1006, Japan \\ 10)Laboratory of Microbiology, Department of Disease Control, Faculty of Veterinary Medicine, \\ Hokkaido University, Kita 18, Nishi 9, Kita-ku, Sapporo, Hokkaido 060-0018, Japan
}

\section{J. Vet. Med. Sci.}

81(4): 577-585, 2019

doi: 10.1292/jvms.18-0671

Received: 14 November 2018 Accepted: 18 February 2019 Published online in J-STAGE: 1 March 2019

\begin{abstract}
Bovine viral diarrhea (BVD) is a chronic disease of cattle caused by infection with $B V D$ virus (BVDV) and can result in economic losses within the livestock industry. In Japan, the test and culling policy is a basic control measure, and implementation of an adequate vaccination program is recommended as a national policy. In addition, optional control measures, including compulsory testing of introduced animals and bulk tank milk (BTM) testing as a mass screening method, are used in several provinces, but their efficacy has not been completely assessed. We evaluated these control measures using the scenario tree model of BVD in Japan, developed in the previous study. The model outputs indicated that compulsory testing of all introduced cattle, rather than only heifers and/or non-vaccinated cattle, was cost effective and reduced the risk of BVDV introduction due to animal movement and that BTM testing could effectively monitor most part of the cattle population. Vaccination coverage and BVDV prevalence among introduced cattle could also affect the cost effectiveness of compulsory testing of targeted cattle, particularly under low vaccination coverage or high BVDV prevalence. However, even with the implementation of a highly effective monitoring scheme for many years, BVD risk could not be eliminated; it instead converged at a very low level $(0.02 \%)$. Disease models with a cost-effective output could be a powerful tool in developing a control scheme for chronic animal diseases, including BVD, with the consent of relevant stakeholders.
\end{abstract}

KEY WORDS: bovine viral diarrhea, cost-effectiveness, scenario tree analysis

*Correspondence to: Sakoda, Y.: sakoda@vetmed.hokudai.ac.jp

O2019 The Japanese Society of Veterinary Science

This is an open-access article distributed under the terms of the Creative Commons Attribution Non-Commercial No Derivatives (by-nc-nd) License. (CC-BY-NC-ND 4.0: https://creativecommons.org/licenses/by-nc-nd/4.o/) 
Bovine viral diarrhea (BVD) is a chronic disease of cattle globally distributed, caused by infection with bovine viral diarrhea virus (BVDV), and results in economic losses to the livestock industry [6, 13-15, 24, 41]. Transient infection (TI) of BVDV in adult ruminants produces subclinical or non-severe symptoms [5, 26]; however, BVDV can be transmitted to the fetus of pregnant cattle between 30 and 120 days of gestation, thereby inducing fetal immune tolerance to BVDV and resulting in the delivery of persistently infected (PI) calves [23]. PI calves shed BVDVs through oculonasal discharge and other secretions throughout their lives, without showing any apparent clinical manifestations, except fatal mucosal disease [4, 7]. PI cattle are commonly believed to be the primary source of BVDV infection in a herd $[15,27]$. Therefore, PI cattle need to be promptly detected and culled for the control of BVD [1].

The ecology of BVD is influenced by feeding style, animal hygiene awareness, and local policy; hence, there is no single effective control intervention that is commonly used worldwide. Scandinavian countries had successfully eradicated BVD approximately 10 years after initiating detection programs for antibodies against BVDVs present in bulk tank milk (BTM) or serum samples and have maintained their BVD-free status ever since [16, 28, 31, 33, 36]. A virus detection system using the ear notch approach has been implemented to detect PI animals in Switzerland [2, 30]. Germany has adopted antigen detection, also mainly using ear notch samples, as well as mass vaccination as an optional biosecurity measure, although optional vaccination has not been widely implemented due to a certain BVDV vaccine causing infection because of bovine neonatal pancytopenia [3,9]. Importation of infected cattle or pregnant PI dams carrying the fetus is considered to be the main route of BVD introduction into BVD-free countries [25]. BTM is widely used in screening tests for BVDV infection in dairy cattle. Vaccination is adopted to a BVD control measure in Japan; hence, detection of BVDV antigens rather than antibodies against BVDV in BTM has been developed and is commonly implemented domestically [20,21].

In Japan, after the identification of BVD being a notifiable disease in 1998, the number of diagnosed cases has stabilized to between 100 and 200 animals per year [21]. According to the latest survey of PI animals in Japanese dairy farms, the proportions of farms with PI animals and of cattle diagnosed as PI animals were 7.6\% [95\% confidence interval (CI): $3.1-16.4 \%]$ and $0.12 \%$ [95\% CI: $0.05-0.25 \%$ ], respectively [21]. Specific control measures, including mass vaccination, screening tests using BTM, and active surveillance for PI cattle, have been voluntarily implemented at areas at a high risk of BVD in collaboration with governments and agricultural parties at the local level $[20,32]$. Each of local governments in Japan is required to select the optional control measures under limited human and financial resources. Implementation of these intensive control measures could markedly reduce risks of BVDV infection in BVD endemic areas; however, the sustainability of these control measures should be focused to maintain a very low or negligible level of BVD risk. Mathematical models dealing with BVD have been developed to enable us to simulate its spread in the area specified in the computer program and to identify factors affecting intra- or inter-herd disease spread $[8,10,12,17,18,39]$. Indeed, simulation analyses of various control measures for BVD in Japan using a stochastic model or a scenario tree were recently reported $[19,35]$; however, the cost effectiveness of the BVD control measures was not fully analyzed.

In the previous study, we developed a scenario tree model to propose efficient BVD control measures using the field data in Nemuro District, eastern part of Hokkaido, where cattle infected with BVDV had been reduced by interventions [19]. The scenario tree with some updates was used in this study to assess cost effectiveness of the BVD control measures, including compulsory testing of introduced animals, and BTM testing as mass screening methods to maintain BVD-free status or low BVD prevalence. The outputs obtained from the model indicated that compulsory testing of only heifers and/or non-vaccinated cattle, rather than all introduced animals, would be a cost-effective way to reduce BVD risk under various scenarios of vaccination coverage or BVDV prevalence and that BTM testing could successfully, but not completely, monitor non-introduced animals. In addition, continuous implementation of each control measure for 15 years was simulated to result in eradication of BVD in Japanese dairy farms.

\section{MATERIALS AND METHODS}

\section{Overview of the analysis}

In Japan, BVD is categorized as a notifiable disease by the Act on Domestic Animal Infectious Disease Control. Once PI cattle are identified by laboratory diagnosis, responsible officers must promptly report them to a competent authority and cull them. Other animals in the same herds must then be tested for BVDV infection (outbreak investigation of newly infected herds). To control BVD in the Japanese cattle population, the Ministry of Agriculture, Forestry and Fisheries in Japan has promoted a vaccination and test and culling policy. In addition, optional measures, including compulsory testing of animals introduced from outside, individual tests prior to communal pasture grazing of animals, and herd screening using BTM, have been implemented in areas where BVD was becoming endemic and regarded as a serious issue that required to be controlled. In this study, considering animal introduction to a target area, we evaluated scenario models with options for compulsory testing of introduced animals and/or BTM testing using a previously developed simulation model. Cost effectiveness of the scenario model and convergence of BVDV prevalence by continuous implementation of the scenario were set as outcomes for each scenario model.

\section{Scenario tree model}

A stochastic scenario tree model comprising nodes representing cattle categorization, immunity following vaccination, virus infection, and monitoring, which had been developed in a previous study, was used here with minor modifications to estimate the number of detected and missed BVDV-infected cattle [19]. Briefly, we presumed that we need to monitor the BVD risk in a target area with cattle movement from outside of the target area and set a number of targeting cattle in this study as a combination of 8,000 inherent cattle in the target area and 2,000 introduced cattle to the target area from outside (introduction ratio; 20\%), 
and both the components of this combination were divided into five age groups based on the immunity status against BVDV, probabilities of detection by clinical manifestation, and availability for lactation. The rates of age distribution in this study were the same as those in the previous study. The default probabilities of cattle being persistently or transiently infected as well as those of possessing sufficient immunity for protection against BVDV infection (both maternal immunity and immunity acquired through vaccination with triple administration) were also the same as those observed in the previous study.

In the default setting, none of cattle introduced from outside was assumed to possess sufficient immunity to protect from BVDV infection because none would have been vaccinated. In several scenarios, a certain proportion of cattle in outside were assumed to be vaccinated; thereby they would possess enough immunity to protect from BVDV infection.

In the default setting, we estimated that PIs and TIs were detected by clinical manifestation or outbreak investigation of newly infected herds. Herd screening using BTM testing was adopted in several scenarios as an optional diagnosis, but individual tests prior to communal pasture grazing were not adopted in this study. All the parameters related to diagnosis, including probability of clinical manifestation in each age group, test sensitivities of each diagnosis, and probability of outbreak investigation, were same as the previous study [19].

A minor addition in this study was that the compulsory testing of introduced animals was applied as an optional control measure. The animals introduced from outside, which satisfied the criteria of a test animal, were assumed to be mandatorily diagnosed with the same test sensitivity as one of outbreak investigation that observed in the previous study, and test-positive animals were automatically culled prior to introduction in this simulation. To evaluate the cost effectiveness of each control measure, products of the unit cost and the number of test animals were calculated for BTM and compulsory testing, and these products were summed as the total cost of the scenario, which would be generally covered by farmers and agricultural parties. On the other hand, the cost of outbreak investigation was not included into the total cost because this is a response mandated by the Act on Domestic Animal Infectious Disease Control in Japan and is covered by the government. A BTM sample of between 100 and 200 cattle is said to be usually used for diagnosis by RT-PCR method. Given that it costs 2,000 JPY to run one RT-PCR reaction, the unit cost of BTM testing would be estimated as 10 to $20 \mathrm{JPY}$. The cost of compulsory testing should be assumed either as 2,000 JPY by RT-PCR or as 1,000 JPY by antigen-detection using ear-notch sample, which is instructed from the manufacturer. Finally, we adopted the cheaper price of each of two tests and set the unit cost of BTM and compulsory testing as 10 JPY and 1,000 JPY per animal, respectively.

The overall probabilities of detected and missed cattle persistently or transiently infected with BVDV (BVD cattle) through the detection sequence set as interventions for BVD control in a default or scenario settings were calculated as a product of the probabilities of infection and all conditional probabilities describing the nodes of each specific detection pathway. The total number of detected and missed BVD cattle as well as the total cost were calculated as outputs of the default or scenarios and were compared to evaluate the efficacy of the measures in each scenario. The scenario tree was developed in an Microsoft Excel (Microsoft, Redmond, WA, U.S.A.) using the software @Risk 6 (Palisade Corp., Newfield, NY, U.S.A.) and was run using 10,000 iterations.

\section{Cost-effective analysis of BVD control measures}

To evaluate the cost effectiveness of the compulsory testing of introduced animals and of BTM testing, scenario models with or without each of these two tests were run, and the number of detected and missed cattle as well as total cost of the measures were calculated. Test objects of compulsory testing of introduced animals was further categorized according to the age of cattle (all or heifers younger than 19 months of age in this study) or the vaccine administration status (all or non-vaccinated). In the scenarios of compulsory testing of non-vaccinated animals, we set a total of five different vaccination coverages $(0,25,50,75$, and $100 \%)$ in outside of the target area.

With an assumption that risk of BVD in inherent cattle in the target area was reduced by the implementation of effective control measures, BVDV prevalence among inherent cattle was changed from $0.4 \%$ as a default setting to either $0.1 \%$ or $0.025 \%$. Probabilities of persistent infection in the scenarios of $0.1 \%$ and $0.025 \%$ inherent BVDV prevalence were set in the model as RiskPert $(0.0005,0.001,0.0015)$ and RiskPert $(0.0002,0.0025,0.0005)$, respectively. Probabilities of transient infection in the scenarios of 0.1 and $0.025 \%$ inherent BVDV prevalence were set to half those of persistent infection in the same scenario.

\section{Fifteen-year forecast of control measure for BVD}

To evaluate the reduction of BVD risk and determine the prevalence of BVD after continuous implementation of the control measure, the scenario models were continuously run. We assumed that the missed cattle in the simulation would be the BVD cattle remaining despite a set of all control measures for an entire year and would be the source of BVDV infection in the next year. The sum of the proportions of missed animals despite a set of all control measures in a scenario and of estimated natural infections per 10,000 animals was regarded as the expected prevalence of BVD among the inherent cattle in the target area in the next year. The estimated number of natural infections was calculated based on the rate of naturally infected herds in a study by Santman-Berends et al. using field data regarding local risk factors of BVD infection in a study by Kadohira et al. [20, 34]. The number of estimated natural infections in this study was set as the product of the number of missed animals and 0.02 , which was defined as the natural infection parameter per BVD cattle. Practically, a set of 5\%,50\%, and 95\% percentiles of the sum of the missed animals and expected natural infections were calculated in each simulation and used for the probability of persistent infection among inherent cattle in the next year as the lower limit, median, and upper limit, respectively. On the other hand, probability of persistent infection among introduced cattle to the target area was fixed at $0.4 \%$ [RiskPert $(0.003,0.004,0.005)]$, which was a default setting. Simulations of each control measure were repeated 15 times with a change of probability in persistent infection. 
A

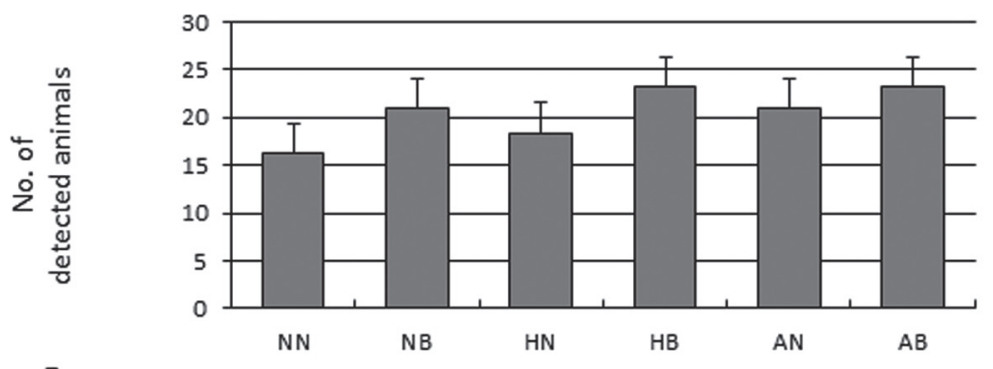

B

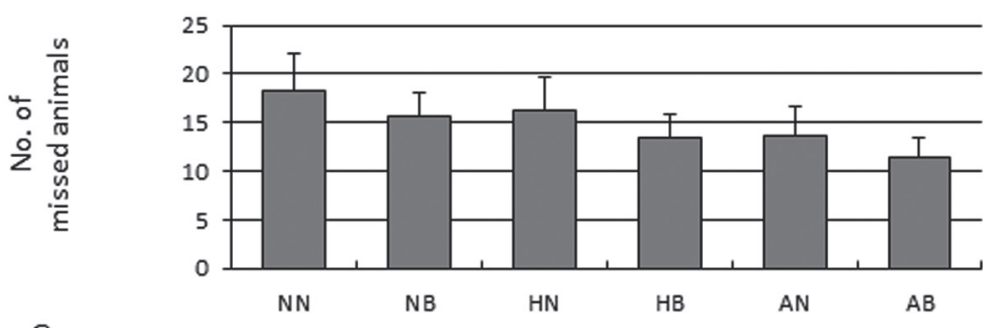

C

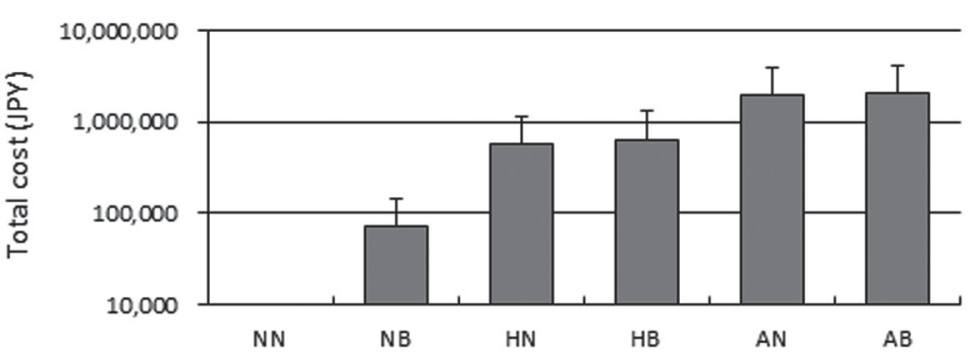

Fig. 1. Evaluation of the control measures. The numbers of detected (A) and missed cattle (B), and total cost (C) in each of six scenarios were compared. NN; implementation of neither compulsory testing of introduced animals nor BTM testing, NB; implementation of BTM testing but no compulsory testing of introduced animals, HN; implementation of compulsory testing of introduced heifers but no BTM testing, HB; implementation of compulsory testing of introduced heifers and BTM testing, AN; implementation of compulsory testing of all introduced animals but no BTM testing, AB; implementation of compulsory testing of all introduced animals and BTM testing. The bar indicates the median number of each output, and the ends of the whiskers of each bar represents 5 th percentiles.

\section{RESULTS}

\section{Efficacy of compulsory testing of introduced animals and BTM testing}

The efficacies of the BVD control measures were evaluated by stochastic simulations. When neither compulsory testing of new introductions nor BTM testing was conducted, the median numbers of detected and missed BVD cattle were 16.2 and 18.3, respectively (Fig. 1). Implementation of BTM testing predicted an increase in the median number of detected cases to 21.0 and a decrease in the median number of missed cases to 15.6. The median of the total cost for this testing was approximately 71,000 JPY.

The median numbers of detected and missed BVD cattle after compulsory testing of introduced heifers were 18.3 and 16.2, respectively. If BTM testing was also implemented, the median number of detected cases increased to 23.2 and the median number of missed cases decreased to 13.5. When comparing efficacy of compulsory testing of heifers with that of all introduced cattle, large differences were observed if BTM testing was not implemented and were not apparently observed if BTM testing was implemented.

Overall, compulsory testing was effective in increasing the number of detected BVD cattle and decreasing the number of missed BVD cattle, although a disadvantage of such compulsory testing was high cost, which was approximately 1,000,000 JPY.

\section{Efficacy of compulsory test of non-vaccinated cattle}

The efficacies of BVD control measures when conducting compulsory tests of non-vaccinated cattle were evaluated with respect to the numbers of detected and missed BVD cattle and the total cost of the tests. Overall, the median number of both detected and missed BVD cattle tended to decrease with increasing vaccination coverage (Fig. 2).

When comparing efficacies of compulsory testing of all cattle with those of only heifers, no large differences were observed in the median numbers of detected or missed BVD cattle cases at any level of vaccination coverage. The gaps in the costs between 
A

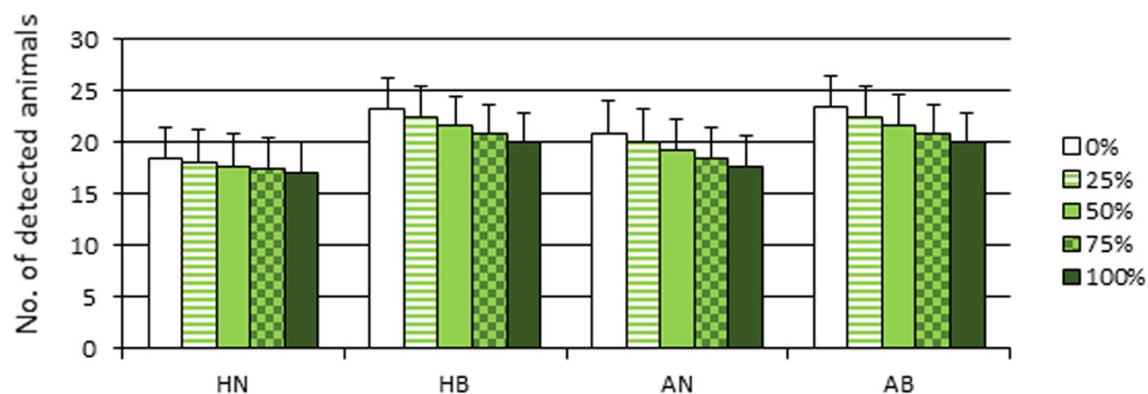

B

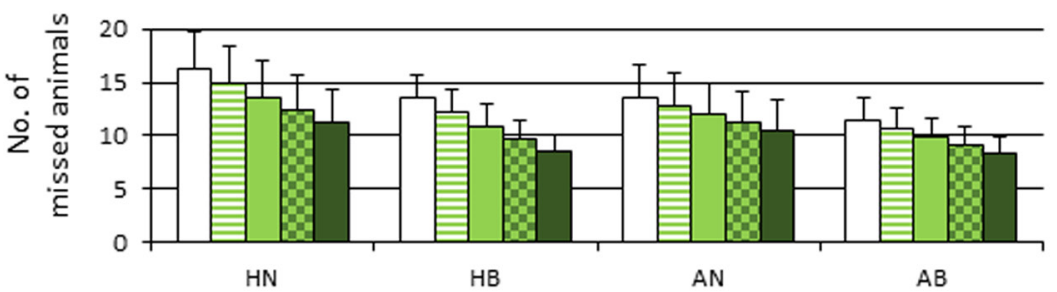

C

$\mathrm{HN}$

$\mathrm{HB}$

AN

$A B$

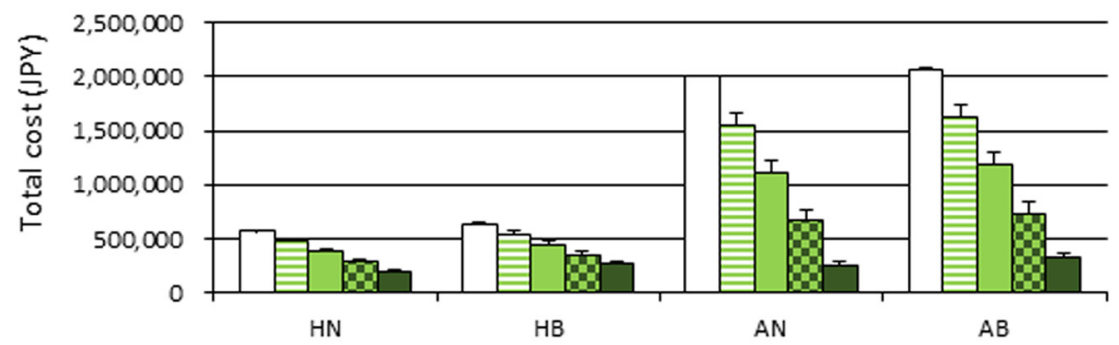

Fig. 2. Evaluation of the control measures in different vaccination coverage in outside. The numbers of detected (A) and missed cattle (B), and total cost $(\mathrm{C})$ in each of four scenarios were compared under each of five vaccination coverages in outside from which animals would be transferred to the target area $(0 \%, 25 \%, 50 \%, 75 \%$, and $100 \%)$. HN; implementation of compulsory testing of introduced non-vaccinated heifers but no BTM testing, HB; implementation of compulsory testing of introduced non-vaccinated heifers and BTM testing, AN; implementation of compulsory testing of all introduced non-vaccinated animals but no BTM testing, AB; implementation of compulsory testing of all introduced non-vaccinated animals and BTM testing. The bar indicates the median number of each output, and the end of the whiskers of each bar represents 5 th percentile.

compulsory testing of non-vaccinated heifers and testing of all non-vaccinated cattle were larger at lower vaccination coverage.

\section{Efficacies of compulsory testing at lower BVDV prevalence}

The efficacy of compulsory testing of non-vaccinated cattle at lower BVDV prevalence was evaluated. The median numbers of detected and missed BVD cattle cases decreased with lower BVDV prevalence (Fig. 3). At a lower BVDV prevalence, the gaps of the median numbers of detected and BVD cattle cases became smaller among the scenarios with different vaccination coverages in outside of the target area, and the same trend was observed in the gaps of the median numbers of missed BVD cattle cases. Moreover, the median numbers of detected BVD cattle by compulsory testing of all non-vaccinated cattle or non-vaccinated heifers were almost same at $0.025 \%$ of BVD prevalence, regardless of vaccination coverage.

\section{Estimated 15-year BVD prevalence}

The predicted 15-year BVD prevalence was simulated under several combinations of control measures. BVD prevalence without implementation of compulsory or BTM testing decreased from $0.4 \%$ to $0.15 \%$ in approximately 10 years (Fig. 4). Implementation of BTM testing estimated the 15-year BVD prevalence to be less than $0.1 \%$. Compulsory testing of heifers affected the decrease in the 15-year BVD prevalence. Implementation of compulsory testing of heifers with and without BTM testing estimated the 15-year BVD prevalence to be approximately $0.06 \%$ and $0.03 \%$, respectively. Compulsory testing of all cattle would result in a very low 15-year BVD prevalence regardless of BTM testing implementation. Implementation of compulsory testing of all cattle with and without BTM testing estimated the 15 -year BVD prevalence approximately $0.03 \%$ and $0.02 \%$, respectively.

The 15-year BVD prevalence after compulsory testing of non-vaccinated heifers when vaccination coverages were set at $50 \%$ and $100 \%$ was estimated to be approximately $0.05 \%$ and $0.04 \%$, respectively (Fig. 5). These figures could decrease to approximately $0.02 \%$ by implementation of BTM testing concurrently. Moreover, the lines predicting BVD prevalence in the scenarios of compulsory testing of all non-vaccinated cattle, regardless of vaccination coverage or implementation of BTM testing, were also terminated in the same figure.

Interestingly, regardless of the target population of compulsory testing, BVD prevalence under the control measure with BTM 
A

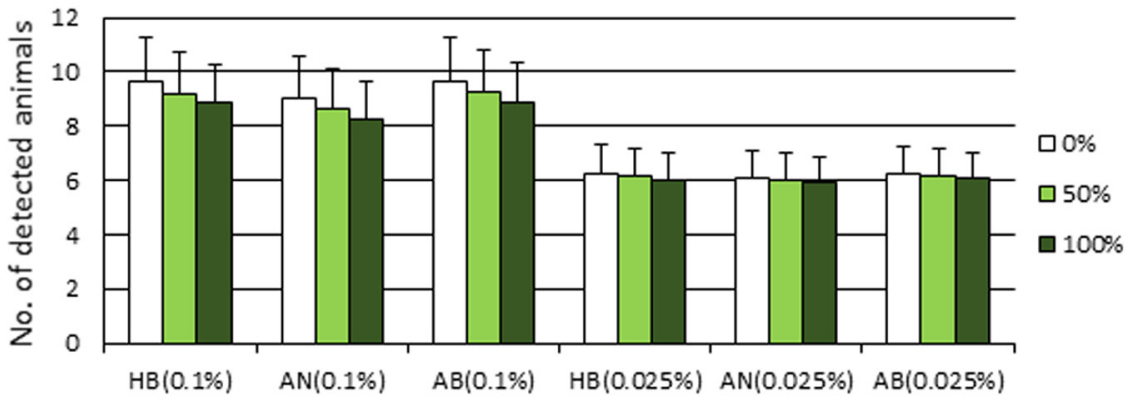

B

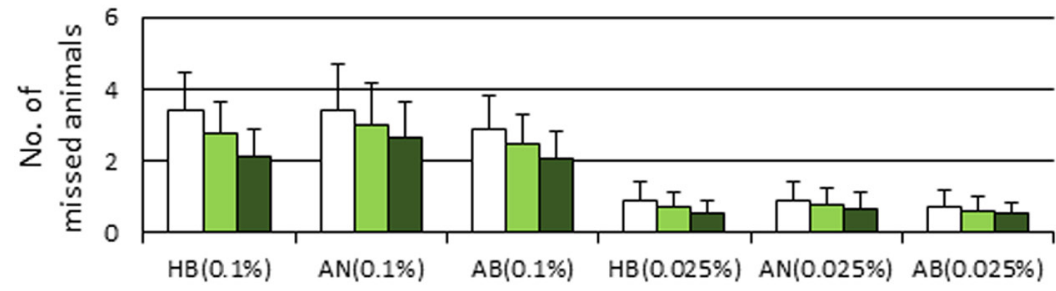

C

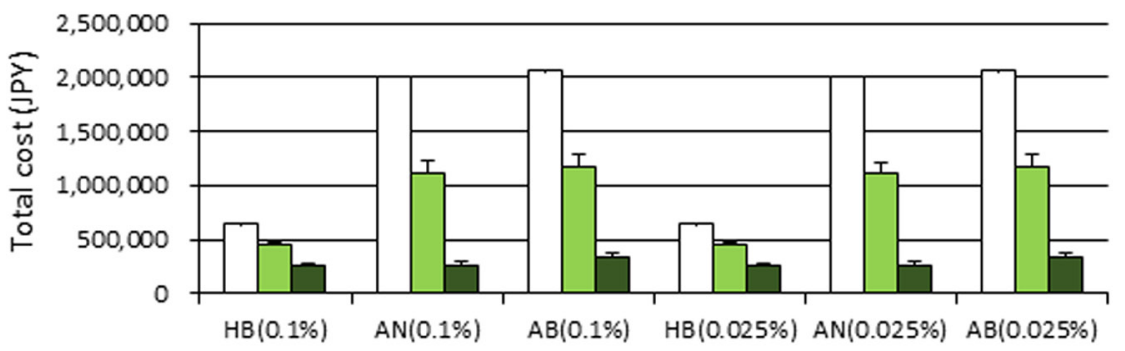

Fig. 3. Evaluation of the control measures under low BVDV prevalence. The number of detected (A) and missed cattle (B) in each of three scenarios were compared under each of three vaccination coverages in outside $(0 \%, 50 \%$, and $100 \%)$, and under each of two BVDV prevalence $(0.1 \%$ or $0.025 \%)$ in the target area. HB; implementation of compulsory testing of introduced non-vaccinated heifers and BTM testing, AN; implementation of compulsory testing of all introduced non-vaccinated animals but no BTM testing, AB; implementation of compulsory testing of all introduced non-vaccinated animals and BTM testing. The bar indicates the median number, and the end of the whiskers of each bar represents 5 th percentile.

testing decreased and converged in a shorter period than that without it, though the process that resulted in BVDV prevalence convergence were different among the scenarios. These results would be a base of politic decision for selection of BVD control measures given the estimated cost for implementation, degree of risk reduction as well as terminated BVDV prevalence.

\section{DISCUSSION}

According to the latest large-scale survey in Japan, seven cattle on six farms tested positive for persistent infection with BVDV among 5,949 cattle from 79 farms analyzed, resulting in 7.59\% (95\% CI: $3.1-16.4 \%$ ) of farms comprising PI animals and $0.12 \%$ of cattle being PI (95\% CI: 0.05-0.25\%) [21]. Four out of six affected farms had not implemented vaccination for one year, and none of the seven PI animals had been vaccinated, indicating that non-vaccination may be a major factor in Japan for persistent BVDV infection in cattle. In addition, the fact that most of the PI animals in the above-mentioned survey were detected in heifers implies the importance of monitoring heifers for BVD control as high priority. Given these points, we aimed to develop scenario models to monitor non-vaccinated animals and/or heifers intensively but cheaply. The results obtained in this study confirmed the efficacy of compulsory testing of introduced animals, and targeting heifers and/or non-vaccinated cattle rather than all cattle, should be sufficient to be efficacious and highly cost effective if BTM tests are implemented concurrently. In addition, more effort might be required to arrange a system to register introduced animals with minimum necessary information including vaccination status, possibility of pregnancy as well as cattle ID in order to grasp the animal introduction accurately. Although BTM testing contributes less to the detection of introduced animals, it should be regarded as a very powerful tool to monitor the entire population inexpensively, and in general, the proportion of lactating cattle to the entire population is much larger than that of introduced animals. In Japan, BTM tests are used for the detection of BVDV genome, which is differing from well-developed antibody detection system in Europe. The effectiveness of BTM tests using antigen monitoring has been widely recognized and reported [20-22]; however, this effective and cheap monitoring program cannot be applied to beef cattle population. Hence, the prevalence of BVD animals in the beef cattle population in Japan might have seldom been reported. A monitoring program for BVD in beef 


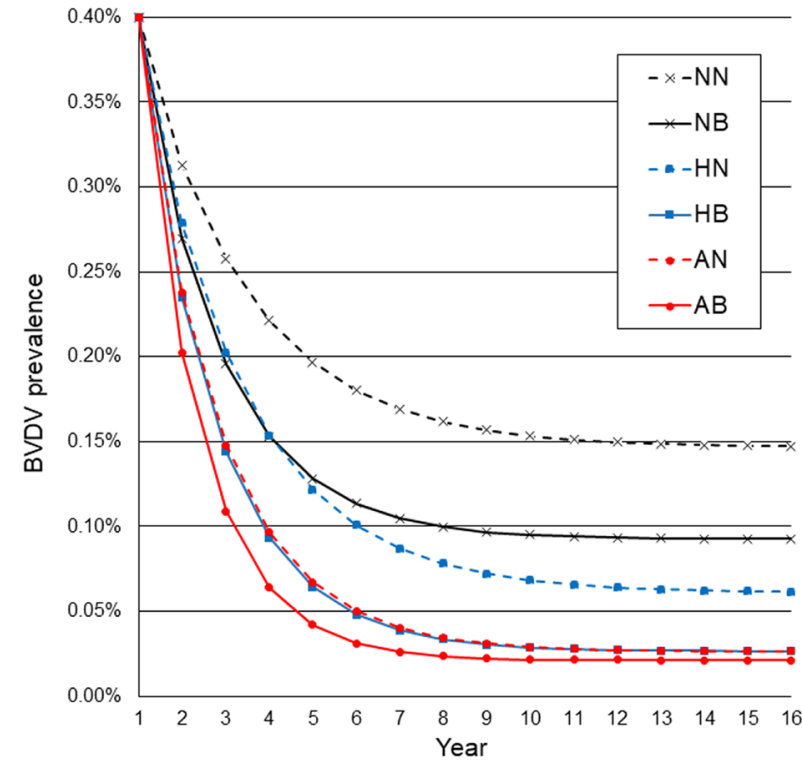

Fig. 4. Simulation of BVDV prevalence after continuous implementation of the control measures. The BVDV prevalence in each year was assumed using the number of missed cattle despite all control measures in the scenario and estimated natural infection. Simulations of each control measure were repeated from $0.40 \%$ of prevalence ( 0 year) to 15 years. Abbreviations of the scenarios were same as ones in Fig. 1.

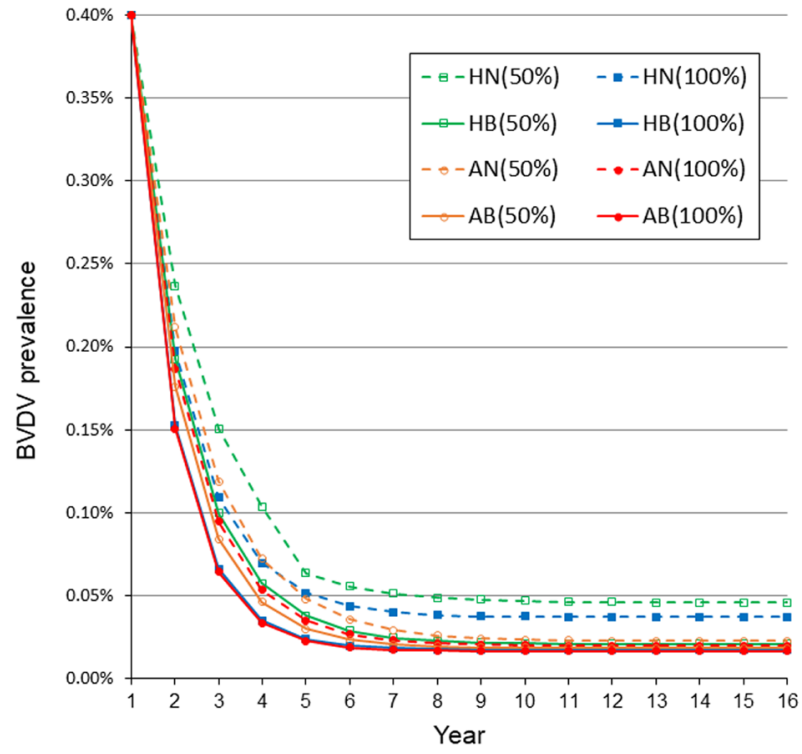

Fig. 5. Simulation of BVDV prevalence after continuous implementation of the control measures in different vaccination coverage in outside. The BVDV prevalence in each year was assumed using the number of missed cattle despite all control measures in the scenario and estimated natural infection. Simulations of each control measure were repeated from $0.40 \%$ of prevalence ( 0 year) to 15 years. Abbreviations of the scenarios were same as ones in Fig. 2.

cattle also needs to be developed to confirm the BVD prevalence among these herds.

In this study, it was observed that lower BVDV prevalence resulted in smaller gaps in vaccination coverages with respect to both the number of detected and missed animals (Fig. 3). Ultimately, under very low BVDV prevalence, the monitoring effectiveness at $0 \%$ of vaccination coverage was not apparently different from that at $100 \%$. These findings may trigger suggestions for reviewing implementation of compulsory testing to introduced non-vaccinated animals because, under very low BVDV prevalence, the efficacy of compulsory testing would be rarely affected by vaccination coverage. It indicates, if efficacy of monitoring programs were not different, many of stakeholders might select the cheaper program to decrease financial burdens. However, this change would require intensive discussion with convincing scientific evidence because it should be implemented under the hypothesis that the very low prevalence of BVDV is maintained by proper biosecurity measures with different stakeholders in outside of the target area. Otherwise, BVDV would spread rapidly among sensitive cattle in outside of the target area that has not been conferred enough immunity to prevent its re-infection by vaccination, and then might be introduced to the target area by animal movement. This would be supported by the model analysis that low compliance with the eradication program owing to lack of proper epidemiological information sharing due to revising the program during its implementation may accelerate BVDV re-infection [38]. Indeed, it is not practical to abolish BVD vaccination in Japan because BVD vaccines, both attenuated or inactivated, are widely used in Japan together with several major virus antigens in cattle as mixed vaccine; hence we cannot quit BVD vaccination easily only due to decrease of BVD prevalence.

This study revealed that a certain proportion of infected cattle could not be removed from the entire population even by monitoring with a highly sensitive test for a long time. This might be due to the retention of PI animals as results of false-negative diagnoses or PI calf delivery from non-PI dams. The prevalence of BVD in cattle decreased to $0.02 \%$ in Switzerland and to $0.03 \%$ in Germany but could not reach zero $[11,40]$. Given the results of the BVD eradication campaign from field data in these two countries, although the goal should be complete eradication, we need to adjust control measures toward a realistic goal for most of the farmers and stakeholders so as to keep motivations for the implementation high. Therefore, the degree of cost effectiveness, rather than possibility of BVD eradication, would become their major concern.

Since BVD is mainly a chronic disease that causes economic losses, including decreased milk production and growth, and respiratory disorders $[14,15,24,41]$, the risk of BVD is not apparent to farmers. Thus, the benefit of control or eradication programs for BVD should be made clear to them to obtain consent for the implementation of strategies such as mass vaccination and biosecurity measures at the regional level. However, because effectiveness of the control measure would require several years to materialize in most cases, maintaining high motivation to sustain the measures is often challenging. In other words, control measures should be implemented with the cooperation of all stakeholders and evaluated prior to commencement as well as during adoption of appropriate program change in response to unexpected occurrences or with respect to the balance between effectiveness 
and expenditure. Although we focused on the cost of voluntary control measures, compulsory testing of introduced animals, and mass screening of BTM, another study calculated the net production losses due to BVDV infection and control expenditures [37]. It should be beneficial to spend control expenditures in a short period if the objective is to reduce net production losses [29]. Thus, an eradication program may not be highly cost effective when it is launched; however, once a disease-free status is achieved, the longer the status is maintained, the more cost effective the program becomes [42]. Cost-effective analysis of net production losses and general hygiene management in Japanese dairy farms should be performed to develop appropriate voluntary BVD control measures in epidemiologically different areas.

In this study, cost effectiveness of optional control measures for BVD, including compulsory testing of introduced animals and BTM testing, were evaluated. The results suggested that the selection of compulsory test animals is critical to increasing cost effectiveness and that BTM testing as a mass screening tool for the entire population is apparently both beneficial and cheap. However, even with a highly effective monitoring scheme, BVD prevalence will not decrease to zero but converge at a very low level. Cost-effective analysis is a powerful tool to develop control measures for chronic animal disease with the consent of stakeholders. More comprehensive cost-effective analysis, in which both expenditure and net production losses are taken into consideration, should prove to be a valuable tool for developing effective animal disease control strategies.

ACKNOWLEDGMENTS. We would like to thank Hokkaido Nemuro Livestock Hygiene Service Center for playing central role of data cooperation with the Betsukai Town Office. We also would like to thank The Federation of Agricultural Cooperatives in Nemuro, and Hokkaido Higashi Agricultural Mutual Aid Association for providing field data and expert opinions regarding husbandry used in this study.

\section{REFERENCES}

1. Abe, Y., Tamura, T., Torii, S., Wakamori, S., Nagai, M., Mitsuhashi, K., Mine, J., Fujimoto, Y., Nagashima, N., Yoshino, F., Sugita, Y., Nomura, T., Okamatsu, M., Kida, H. and Sakoda, Y. 2016. Genetic and antigenic characterization of bovine viral diarrhea viruses isolated from cattle in Hokkaido, Japan. J. Vet. Med. Sci. 78: 61-70. [Medline] [CrossRef]

2. Barrett, D. J., More, S. J., Graham, D. A., O'Flaherty, J., Doherty, M. L. and Gunn, H. M. 2011. Considerations on BVD eradication for the Irish livestock industry. Ir. Vet. J. 64: 12. [Medline] [CrossRef]

3. Bastian, M., Holsteg, M., Hanke-Robinson, H., Duchow, K. and Cussler, K. 2011. Bovine Neonatal Pancytopenia: is this alloimmune syndrome caused by vaccine-induced alloreactive antibodies? Vaccine 29: 5267-5275. [Medline] [CrossRef]

4. Brownlie, J. 1991. The pathways for bovine virus diarrhoea virus biotypes in the pathogenesis of disease. Arch. Virol. Suppl. 3: 79-96. [Medline] [CrossRef]

5. Brownlie, J., Clarke, M. C. and Howard, C. J. 1984. Experimental production of fatal mucosal disease in cattle. Vet. Rec. 114: 535-536. [Medline] [CrossRef]

6. Castrucci, G., Ferrari, M., Traldi, V. and Tartaglione, E. 1992. Effects in calves of mixed infections with bovine viral diarrhea virus and several other bovine viruses. Comp. Immunol. Microbiol. Infect. Dis. 15: 261-270. [Medline] [CrossRef]

7. Confer, A. W., Fulton, R. W., Step, D. L., Johnson, B. J. and Ridpath, J. F. 2005. Viral antigen distribution in the respiratory tract of cattle persistently infected with bovine viral diarrhea virus subtype 2a. Vet. Pathol. 42: 192-199. [Medline] [CrossRef]

8. Damman, A., Viet, A. F., Arnoux, S., Guerrier-Chatellet, M. C., Petit, E. and Ezanno, P. 2015. Modelling the spread of bovine viral diarrhea virus (BVDV) in a beef cattle herd and its impact on herd productivity. Vet. Res. (Faisalabad) 46: 12. [Medline] [CrossRef]

9. Deutskens, F., Lamp, B., Riedel, C. M., Wentz, E., Lochnit, G., Doll, K., Thiel, H. J. and Rümenapf, T. 2011. Vaccine-induced antibodies linked to bovine neonatal pancytopenia (BNP) recognize cattle major histocompatibility complex class I (MHC I). Vet. Res. (Faisalabad) 42: 97. [Medline] [CrossRef]

10. Ezanno, P., Fourichon, C., Viet, A. F. and Seegers, H. 2007. Sensitivity analysis to identify key-parameters in modelling the spread of bovine viral diarrhoea virus in a dairy herd. Prev. Vet. Med. 80: 49-64. [Medline] [CrossRef]

11. FSVO 2016. BVD-Ausrottungsprogramm 2008-2012, ed., Federal Food Safety andVeterinary Office, Bern, Switzerland.

12. Gates, M. C., Humphry, R. W., Gunn, G. J. and Woolhouse, M. E. 2014. Not all cows are epidemiologically equal: quantifying the risks of bovine viral diarrhoea virus (BVDV) transmission through cattle movements. Vet. Res. (Faisalabad) 45: 110. [Medline] [CrossRef]

13. Gillespie, J. H., Baker, J. A. and McENTEE, K. 1960. A cytopathogenic strain of virus diarrhea virus. Cornell Vet. 50: 73-79. [Medline]

14. Hessman, B. E., Fulton, R. W., Sjeklocha, D. B., Murphy, T. A., Ridpath, J. F. and Payton, M. E. 2009. Evaluation of economic effects and the health and performance of the general cattle population after exposure to cattle persistently infected with bovine viral diarrhea virus in a starter feedlot. Am. J. Vet. Res. 70: 73-85. [Medline] [CrossRef]

15. Houe, H. 1999. Epidemiological features and economical importance of bovine virus diarrhoea virus (BVDV) infections. Vet. Microbiol. 64: 89-107. [Medline] [CrossRef]

16. Hult, L. and Lindberg, A. 2005. Experiences from BVDV control in Sweden. Prev. Vet. Med. 72: 143-148, discussion 215-219. [Medline] [CrossRef]

17. Innocent, G., Morrison, I., Brownlie, J. and Gettinby, G. 1997. The use of a mass-action model to validate the output from a stochastic simulation model of bovine viral diarrhoea virus spread in a closed dairy herd. Prev. Vet. Med. 31: 199-209. [Medline] [CrossRef]

18. Innocent, G., Morrison, I., Brownlie, J. and Gettinby, G. 1997. A computer simulation of the transmission dynamics and the effects of duration of immunity and survival of persistently infected animals on the spread of bovine viral diarrhoea virus in dairy cattle. Epidemiol. Infect. 119: 91-100. [Medline] [CrossRef]

19. Isoda, N., Asano, A., Ichijo, M., Wakamori, S., Ohno, H., Sato, K., Okamoto, H., Nakao, S., Kato, H., Saito, K., Ito, N., Usui, A., Takayama, H. and Sakoda, Y. 2017. Evaluation of control measures for bovine viral diarrhea implemented in Nemuro District, Hokkaido, Japan, using a scenario tree model. J. Vet. Med. Sci. 79: 1172-1181. [Medline] [CrossRef]

20. Kadohira, M. and Tajima, M. 2010. A case control study of Bovine Viral Diarrhea Virus (BVDV) Persistent Infection (PI) in Betsukai, Hokkaido, Japan. J. Vet. Med. Sci. 72: 635-638. [Medline] [CrossRef] 
21. Kameyama, K., Konishi, M., Tsutsui, T. and Yamamoto, T. 2016. Survey for detecting persistently infected cattle with bovine viral diarrhea in Japan. J. Vet. Med. Sci. 78: 1329-1331. [Medline] [CrossRef]

22. Kozasa, T., Tajima, M., Yasutomi, I., Sano, K., Ohashi, K. and Onuma, M. 2005. Relationship of bovine viral diarrhea virus persistent infection to incidence of diseases on dairy farms based on bulk tank milk test by RT-PCR. Vet. Microbiol. 106: 41-47. [Medline] [CrossRef]

23. Lanyon, S. R., Hill, F. I., Reichel, M. P. and Brownlie, J. 2014. Bovine viral diarrhoea: pathogenesis and diagnosis. Vet. J. 199: 201-209. [Medline] [CrossRef]

24. Larson, R. L., Pierce, V. L., Grotelueschen, D. M. and Wittum, T. E. 2002. Economic evaluation of beef cowherd screeing for cattle persistentlyinfected with bovine viral diarrhea virus. Bov. Pract. 36: 106-112.

25. Lindberg, A., Brownlie, J., Gunn, G. J., Houe, H., Moennig, V., Saatkamp, H. W., Sandvik, T. and Valle, P. S. 2006. The control of bovine viral diarrhoea virus in Europe: today and in the future. Rev. - Off. Int. Epizoot. 25: 961-979. [Medline] [CrossRef]

26. McClurkin, A. W., Bolin, S. R. and Coria, M. F. 1985. Isolation of cytopathic and noncytopathic bovine viral diarrhea virus from the spleen of cattle acutely and chronically affected with bovine viral diarrhea. J. Am. Vet. Med. Assoc. 186: 568-569. [Medline]

27. Niskanen, R., Lindberg, A. and Tråvén, M. 2002. Failure to spread bovine virus diarrhoea virus infection from primarily infected calves despite concurrent infection with bovine coronavirus. Vet. J. 163: 251-259. [Medline] [CrossRef]

28. Nyberg, O., Osteras, O. and Plym-Forshell, K. 2004. Eradication of BVDV-infections in Norwegian cattle 1992-2003: a success story. Revista Portugueesa de ciencias veterinarias 127(Supple): 14-15.

29. Otte, M. and Chilonda, P. 2011. Animal health economics: an introduction of animal information, sector analysis and policy branch, animal production and health division, ed., Rome: Food and Agricultural Organization of the United Nations.

30. Presi, P. and Heim, D. 2010. BVD eradication in Switzerland--a new approach. Vet. Microbiol. 142: 137-142. [Medline] [CrossRef]

31. Rikula, U., Nuotio, L., Aaltonen, T. and Ruoho, O. 2005. Bovine viral diarrhoea virus control in Finland 1998-2004. Prev. Vet. Med. 72: 139-142, discussion 215-219. [Medline] [CrossRef]

32. Saino, H., Kawauchi, K., Usui, A., Ohno, H., Sakoda, Y. and Tajima, M. 2013. Implementation and verification of the effectiveness of a regional control program for bovine viral diarrhea virus infection in Hokkaido, Japan. Nippon Juishikai Zasshi 66: 791-796.

33. Sandvik, T. 2004. Progress of control and prevention programs for bovine viral diarrhea virus in Europe. Vet. Clin. North Am. Food Anim. Pract. 20: 151-169. [Medline] [CrossRef]

34. Santman-Berends, I. M., Mars, M. H., van Duijn, L. and van Schaik, G. 2015. Evaluation of the epidemiological and economic consequences of control scenarios for bovine viral diarrhea virus in dairy herds. J. Dairy Sci. 98: 7699-7716. [Medline] [CrossRef]

35. Sekiguchi, S., Presi, P., Omori, R., Staerk, K., Schuppers, M., Isoda, N., Yoshikawa, Y., Umemura, T., Nakayama, H., Fujii, Y. and Sakoda, Y. 2018. Evaluation of bovine viral diarrhoea virus control strategies in dairy herds in Hokkaido, Japan, using stochastic modelling. Transbound. Emerg. Dis. 65: e135-e144. [Medline] [CrossRef]

36. Ståhl, K. and Alenius, S. 2012. BVDV control and eradication in Europe--an update. Jpn. J. Vet. Res. 60 Suppl: S31-S39. [Medline]

37. Thomann, B., Tschopp, A., Magouras, I., Meylan, M., Schüpbach-Regula, G. and Häsler, B. 2017. Economic evaluation of the eradication program for bovine viral diarrhea in the Swiss dairy sector. Prev. Vet. Med. 145: 1-6. [Medline] [CrossRef]

38. Thulke, H. H., Lange, M., Tratalos, J. A., Clegg, T. A., McGrath, G., O’Grady, L., O’Sullivan, P., Doherty, M. L., Graham, D. A. and More, S. J. 2018. Eradicating BVD, reviewing Irish programme data and model predictions to support prospective decision making. Prev. Vet. Med. 150: 151-161. [Medline] [CrossRef]

39. Tinsley, M., Lewis, F. I. and Brülisauer, F. 2012. Network modeling of BVD transmission. Vet. Res. (Faisalabad) 43: 11. [Medline] [CrossRef]

40. Wernike, K., Gethmann, J., Schirrmeier, H., Schröder, R., Conraths, F. J. and Beer, M. 2017. Six Years (2011-2016) of mandatory nationwide bovine viral diarrhea control in Germany-a success story. Pathogens 6: 6. [Medline] [CrossRef]

41. Wittum, T. E., Salman, M. D., King, M. E., Mortimer, R. G., Odde, K. G. and Morris, D. L. 1994. The influence of neonatal health on weaning weight of Colorado, U.S.A. beef calves. Prev. Vet. Med. 49: 83-94. [Medline] [CrossRef]

42. Yarnall, M. J. and Thrusfield, M. V. 2017. Engaging veterinarians and farmers in eradicating bovine viral diarrhoea: a systematic review of economic impact. Vet. Rec. 181: 347. [Medline] [CrossRef] 